\title{
"Stepping up to the plate": Identifying cultural competencies when providing health care to Canada's military and Veteran families
}

\author{
Linna Tam-Seto ${ }^{a}$, Terry Krupa ${ }^{\mathrm{b}}$, Heather Stuart ${ }^{\mathrm{c}}$, Patricia Lingley-Pottie ${ }^{\mathrm{d}}$, Alice Aiken ${ }^{\mathrm{e}}$ and Heidi \\ Cramm $^{\mathrm{b}}$
}

\begin{abstract}
Introduction: Military family life is characterized by frequent relocations, regular periods of separation, and living with the persistent risk of injury or death of their military family member. The cumulative effects of these life events impact the health and wellness of military and Veteran families (MVFs) and may be exacerbated by challenges of accessing and navigating new health care systems when families relocate or when confronted with health care providers (HCPs) unaware of their experiences. Developing cultural competency in HCPs has been found to be beneficial to both the service provider and the service user. The purpose of this study is to identify cultural competencies for HCPs who work with MVFs. Methods: We completed a qualitative study using critical incident one-on-one interviews with HCPs. We used framework analysis for data analysis. Results: In total, we completed nine interviews with HCPs who have experience working with MVFs. Cultural competencies were identified in the domains of cultural awareness, cultural sensitivity, cultural knowledge, and cultural skills. Evidence also indicates the role of the ecological context on the ability of HCPs to be culturally competent. Discussion: Necessary competencies have been identified when providing culturally competent care to MVFs. The results highlight the need for MVF cultural competency training during pre-service health professional curricula and continuing education. We have acknowledged the need for policy and regulatory changes to facilitate the access and utilization of culturally informed health care. Finally, the cultural competencies identified will contribute to the development of an MVF cultural competency model for HCPs working in Canada.
\end{abstract}

Key words: Canadian Armed Forces (CAF), cultural competency, health care delivery, health care professional, knowledge translation, military culture, military and Veteran families, qualitative research

\section{RÉSUMÉ}

Introduction : La vie des familles de militaires se caractérise par de fréquents déménagements, des périodes régulières de séparation et le risque persistant de décès du militaire de la famille. Les effets cumulatifs de ces événements ont un impact sur la santé et le bien-être des familles de militaires et de vétérans (FMV) et peuvent être exacerbés par les difficultés d'accès aux nouveaux systèmes de santé ou à se retrouver dans ces systèmes à chaque déménagement ou lors de la rencontre de professionnels de la santé (PdS) qui ne sont pas au courant de leurs expériences. L'acquisition de compétences culturelles de la part du PdS se révèle bénéfique à la fois pour celui-ci et pour l'utilisateur du service. La présente étude vise à déterminer les compétences culturelles que doivent posséder les PdS qui travaillent avec des FMV. Méthodologie : Les chercheurs ont procédé à une analyse qualitative au moyen d'entrevues individuelles sur les incidents critiques auprès des PdS. Ils ont utilisé la méthode du cadre logique pour analyser les données. Résultats : Au total, les chercheurs ont effectué neuf entrevues auprès de PdS qui avaient une expérience de travail avec des FMV. Ils ont constaté des compétences culturelles dans les domaines suivants: sensibilisation aux cultures, sensibilisation aux réalités culturelles, connaissances culturelles et habiletés culturelles. Les données probantes indiquent également le rôle du contexte écologique sur la capacité des PdS à faire preuve de compétence culturelle. Discussion : Les chercheurs ont

\footnotetext{
Queen's University, Health Services \& Policy Studies Institute, Kingston

Queen's University, School of Rehabilitation Therapy, Kingston

Queen's University, Department of Public Health Sciences, Kingston

Dalhousie University, Department of Psychiatry, Halifax

Dalhousie University, Faculty of Health Professions, Halifax
}

Correspondence should be addressed to Linna Tam-Seto at linna.tam-seto@queensu.ca 
déterminé les compétences nécessaires pour donner des soins compétents sur le plan culturel aux FMV. Les résultats font ressortir l'importance de donner une formation aux PdS sur les compétences culturelles auprès des FMV dans le cadre du cursus universitaire et de la formation continue. La nécessité d'apporter des modifications aux politiques et à la réglementation pour faciliter l'accès à des soins respectueux de la culture et l'utilisation de ces soins est établie. Enfin, les compétences culturelles déterminées contribueront à l'acquisition d'un modèle de compétences culturelles auprès des FMV pour les PdS qui travaillent au Canada.

Mots-clés : compétence culturelle, culture militaire, familles de vétérans et de militaires, prestation des soins, recherche qualitative, Forces armées canadiennes (FAC), application des connaissances

\section{INTRODUCTION}

The Ombudsman report highlights that in isolation, mobility, separation, and risk are not unique to Canadian Armed Forces members, Veterans, and their families; however, "when combined, the distinctiveness of the military career become more obvious"' because "few occupations ... expose the overwhelming majority of its people to recurring geographic relocation, relentless separation and elevated levels of risk as a matter of course throughout much of their careers." 1 As one of the many recommendations made to better support military and Veteran families (MVFs), this report puts forth a call to "assist military families to obtain better access to health care."

To increase our understanding of MVFs within the greater Canadian population, more attention to military culture and its impact on health is required. Not only are military members and Veterans united by the shared experience of living within a distinct culture; so are the spouses, partners, children, and other family members. ${ }^{2-5}$ The need for military cultural competency among health care providers is being discussed in the American literature. ${ }^{2,6-12}$ Military cultural competency is the "degree to which providers are sensitive to the unique needs and relevant issues of concern within the [military and] Veteran population.." ${ }^{12}$ However, in order for health care providers (HCPs) to develop cultural competency, they must first believe that the military is a culture characterized by its own practices, attitudes, beliefs, language, traditions, and values. ${ }^{2-5}$ Also, it is important for HCPs to understand the impacts of military life events such as mobility, separation, and risk on spouses, children, and family relationships. ${ }^{13}$ Providing military cultural competency education for health care professionals about the specific health knowledge, skills, and behaviours ${ }^{6}$ can positively influence practice, enhancing the health care experience of military and Veteran families ${ }^{7,13}$

The development and use of models and frameworks are approaches used to support the journey toward cultural competency. ${ }^{14-18}$ Competency models and frameworks describe the knowledge, skills, abilities, or personal traits required for a specific job or function. ${ }^{19-21}$ The degree to which the existing international military cultural competency models and frameworks $s^{12,22,23}$ can be applied to the health care experience of Canadian military and Veteran families is limited due to differences in military life events and how health care services are accessed. Canadian health care associations are recognizing the need to better support the health care experiences of MVFs through publications calling for more action, development of resources for their members, and collaborations with military research and advocacy organizations. Canadian health professions joining the cause include medicine, ${ }^{24-25}$ occupational therapy, ${ }^{26-29}$ social work, ${ }^{30}$ psychology, ${ }^{31}$ and nursing. ${ }^{32}$

Given the gaps identified in the Canadian literature, the recognition of the importance for military cultural competency in health care practice, and the prioritization of the health of military members, Veterans, and their families among Canadian health professional associations, it is imperative to conduct research to answer the question: "What are the cultural competencies identified by HCPs when working with Canadian military and Veteran families?"

\section{METHODS}

The constructivist perspective taken in this qualitative study is well-suited for increasing the understanding of the diverse experiences of Canadian HCPs working with military and Veteran families. Constructivism takes the stance that reality is created through a number of different perspectives.33

\section{Data collection}

The exploratory and constructivist nature of this study and paradigmatic positioning of the thesis makes critical incident technique (CIT) an appropriate method for data collection. CIT served as the foundation for the in-depth interviews used in the study and well-suited as it is considered effective for further developing a body of knowledge in an area where little is known. ${ }^{34,35}$ This 
method of data collection allows participants to describe and reflect on a specific incident which is defined as "any observable human activity that is sufficiently complete in itself that permits inference and predictions to be made about the person performing the act." ${ }^{36}$ It is considered critical when the intent and outcome of the incident is clear and there is no uncertainty of its effects. CIT enables participants to reflect on specific health care interactions to identify particular cultural competencies informing the care they provide to MVFs.

An interview guide was developed by the authors, and questions were subject to informal review with two participants (a family physician and a registered nurse). The questions were refined for further clarification. The data collected during the pilot study were not included in this study. Interview questions were only specific enough to elicit recollection and description of critical incidents. Additional probing questions were used to explore the incident details. Participants were also asked to describe steps they had taken to become more culturally competent in their practice.

The study protocol was granted ethical clearance by the Institution's research ethics board. All participants provided written consent. Prior to the interviews, the first author reviewed the consent procedure and provided participants with the opportunity to ask questions.

Purposive sampling was used to recruit health professionals working in Canada with experience working with military members, Veterans and/or their family members as they have knowledge of the health care interactions with MVFs. ${ }^{20,37}$ The inclusion criterion was the following: HCPs with experience working with family members of serving Canadian Armed Forces (CAF) members or CAF Veterans and English-speaking. Recruitment methods included posting and sharing a recruitment flyer on social media pages (i.e., Twitter, Facebook) aimed at informing the MVF research community and health professionals about current research studies and snowball sampling.

All interviews were conducted over the telephone and were audio recorded and transcribed verbatim. Interviews were conducted between May and August 2017. Interviews averaged 45 minutes in length.

\section{Data analysis}

Framework analysis was used for data analysis as this method is suitable when there is a little information available in a given area and when the required information is intended for use for a specific purpose. ${ }^{38}$ Framework analysis involves sorting and charting information according to key issues and themes in five distinct phases: familiarization; identifying a thematic framework; indexing; charting; and mapping and interpretation. ${ }^{38} \mathrm{Fa}$ miliarizing involves becoming closely acquainted with the data through listening to interviews and reading transcripts $^{38}$ followed by developing a thematic framework $^{38}$ which involves drawing upon a priori items and emergent issues to create a guide in which the data are organized. The results of a scoping review, was used to inform the categories of the thematic framework. Four distinct yet interconnected cultural competency domains were identified in the scoping review: cultural awareness, cultural sensitivity, cultural knowledge, and cultural skills. Although not a cultural competency domain, the ecological context has been identified in the cultural competency health care literature as facilitating or hinder the cultural competent care. ${ }^{14,39,40,41}$

The remaining steps of framework analysis included indexing, charting, and mapping and interpretations, and were completed to identify themes and sub-themes. MAXQDA software ${ }^{42}$ was used to assist with data management.

\section{RESULTS}

In total, 9 interviews were completed, including 1 registered nurse; 1 social worker; 1 psychiatrist; 3 occupational therapists; and 3 pediatricians. The participants resided in western, central, and eastern Canada. There was evidence in the data that all four cultural competency domains, cultural awareness, cultural sensitivity, cultural knowledge, and cultural skills, were practiced. There were also factors residing within the ecological context that could either facilitate or hinder culturally competent practice.

\section{Cultural awareness}

Cultural awareness (known hereafter as awareness) was evident in the care described by all participants. Subthemes that emerged included recognizing the military as a culture, perceptions and views toward military and Veteran families, and ongoing self-reflection.

\section{Recognizing the military as a culture}

With the exception of one participant who is currently part of a military family, all other participants $(n=8)$ learned about military family lifestyle through their roles as HCPs. Differences were commented on by a number of participants, with one stating that "[military families] are a very unique set of families ... the families are 
unique in many ways," while another acknowledged that "their lived experiences are completely different than ours if we've never been in the military." In addition, participants also understood that these unique experiences contribute to defining MVFs as a culture acknowledging that "when you're part of it, it's not just one part of your [life], it's their whole life." While participants acknowledged the military as a culture and that MVFs belong within that culture, they also engaged in opportunities to look at their own perceptions towards MVFs.

\section{Perceptions and views of military and Veteran families}

When developing awareness, participants described examining their own perceptions of military life and MVFs. Many of the participants remarked on being opened-minded when they first began working with MVFs. One participant stated that she had "very little expectation of, or understanding of what to expect," while another reported that she "came in with a bit of a fresh slate." When participants acknowledge having pre-determined perceptions of military families, they were often based on information from sources out of the United States, including how and where MVFs access health care services. Assumptions were also made by HCP that certain health conditions are more common in military families, including anxiety and depression.

\section{Ongoing self-reflection}

All participants described a process of reflecting on how being civilians affected their health care interactions with MVFs. In addition, participants also reflected on their own professional culture, acknowledging the potential impact it has on their work. One participant shared that as a social worker, she was trained to want to help families because they needed help and not necessarily because they were military families. This view of families is reportedly consistent with the beliefs and values of the social work profession. ${ }^{43}$ Being client-centred and holistic in their occupational therapy practice, two participants described how their profession has informed their practice with MVFs. One participant commented on how her profession's view toward holistic client care makes her "consciously aware [when] someone [is] coming to the door that I need to read and listen to them." The process described by participants when beginning work with MVFs involved recognition that families are part of the military culture and engaging in ongoing opportunities to reflect on their own perceptions towards them.

\section{Cultural sensitivity}

Participants described several aspects of cultural sensitivity (known hereafter as sensitivity) including the motivation to provide culturally-informed health care as well as to develop knowledge and skills.

\section{Motivation to provide culturally-informed health care}

All participants were motivated to provide health care that met the unique needs of MVFs. Participants also described feeling a sense of honour when working with this particular population. One participant shared:

[There is] this sort of urgency that one feels with working with military families where you're like, this is my moment in time with this family, and wanting to do justice to being able to help them out, you know?

With an underlying desire to provide care that is appropriate for MVFs, participants understood they also needed to enter the health relationship with a sense of humility, as stated by another participant:

You know, really being respectful of that: Their experience is theirs. And not having been through that, you know, I would sort of, have to earn their trust and respect any differently.

The desire to provide culturally competent health care led participants to pursue knowledge and skills that fit the needs and circumstances of the MVFs within their practice.

\section{Motivation to develop cultural knowledge and cultural skills}

All participants described a motivation to further advance their knowledge about MVFs and augment their skills related to the care they provide. A gap in formal education and continuing education was identified by participations. Like all participants in this study, this health care provider described learning about the lives of MVFs through his work:

I never got formal training on the military. I had to self-teach. I had to learn. Initially by just experience and then afterwards by reading articles and journals and things like that. It's something I've learned over the years.

Because of the lack of information provided to her during her formal education, another participant compiled evidence-based resources to facilitate the development of MVF knowledge and skill in her trainees: 
So, now I take residents as learners and I always make them read that [Canadian Paediatric Society Position] Statement and say, "This particular family is coming," or "We've set up a clinic with the Military Family Resource Centre and I want you to think about the risk factors and the questions you might ask, particular to this population, that you wouldn't have considered before, not knowing about how the health care was delivered and the frequency of moves and deployments, and stuff."

Sensitivity, the inclination to address the differences in health care provision to MVFs, was evident in the participants

\section{Cultural knowledge}

Cultural knowledge (known hereafter as knowledge) was acquired both formally (e.g., association position statements, international research) and informally (e.g., consulting with colleagues/peers, speaking with MVFs). Knowledge is described in the following sub-themes: the impact of military family life events on health and health care experiences; and effects of military/Veteran member's health on family.

\section{The impact of military family life events on health and health care experiences}

Military family life events - such as frequent mobility, familial separation, and living with the risk of injury or death of a military family member - are situations that participants encountered in their work with MVFs. Participants noted how these events have impacted the health of family members and how families access and use health care services.

Frequent mobility was named as the main cause for disruption and fragmented maintenance of health care services. Because of her own personal experience as a military spouse, this participant understood the effects of frequent mobility on how families access health care services in their new posting if families are not arriving with all of their health information:

[I] can also give tips to families [on how they] can obtain their immunization records and, a lot of that knowledge, [that] I've gained from my own self, having moved so often. It's very difficult for inter-provincial moves trying to get your own immunization records, so for me, it [has been] helpful as a spouse and as a health care provider to help them get their family organized, as well. It's very difficult sometimes.

For professions who are focused primarily on the health and well-being of children and youth, the inclusion of parents is important. Military familial separation due to training exercises or operational deployment has also been noted as impacting the health of the family members who remain at home. This participant shared:

[The military parent is] sent to Afghanistan. Sent to wherever. So, you have a lot of tension and anxiety within the kids when mum, when mum or dad is posted for 6 months. That's another common occurrence. And it's obviously quite different than what I have in a civilian family.

Participants acknowledged the health impacts of military family members living with the persistent risk of injury or death of their military family member. For some participants, it has been their experience of seeing how operational stress injuries such as posttraumatic stress disorder (PTSD) can affect family members. One participant described an experience with one particular family living with this reality:

But with this family, as with all others, you know, the parent having quite severe posttraumatic stress syndrome adds a big layer of, of stress and tension to the home that isn't typical of a civilian family. Just the reality of that military PTSD is stressful for parents and children alike.

All participants acknowledged that military life events such as mobility, separation, and risk can affect health and health care experiences; in addition, participants also noted that the health of the military family member also affected the health of their family members.

\section{Effects of military/Veteran member's health on family}

Participants reported that, in their work with MVFs, the military member or Veteran's illness also affected individual family members as well as the family as a whole. Like many other participants, this participant was initially unaware of the link between the military member's health and the family:

[Research papers] are frequently written by military docs who talk about care of children and other things like that, so it's, um, more inter-fused. I don't know that, as I was going through my training, I had such an awareness of the impacts of issues like PTSD in parents on children, either. That's just something real life has taught me.

Having noticed how the well-being of military members and Veterans impacts the health of their family 
members, participants shared their concern for greater commitment to better understand this relationship. One participant stated that:

We need to investigate this group of people because I think they have a very, very high prevalence of mental health issues and their children do, also. I believe that there's an association between stress in families, toxic stress, which is what they go through, and things like [developmental delays]...so we need to be very much looking at these folks and being aware that there are things that we need to be cognizant of when we're dealing with these families.

Participants described how the increase in their knowledge base of MVFs helped develop clinical skills when working with this population.

\section{Cultural skills}

Cultural skills (known hereafter as skills) were also identified when health care interactions with MVFs were described. Specific skills employed included: building a trusting relationship; and being creative and flexible during care.

\section{Building a trusting relationship}

Although building a trusting relationship is important to any health care interaction, participants described additional efforts made in establishing and maintaining a relationship. One of the challenges faced by participants was the view that they were outsiders, HCPs who neither understood nor appreciated the experiences of military family life. One participant expressed her concern about being viewed as such when working with families, and how this may affect developing a therapeutic relationship when she shared:

I don't know but I'm going to, I'm going to surmise that they're like, "Well, holy shit, couldn't they have sent me, like, and effing OT who served in the military who knows what the Hell and who to talk to and how it works?"

Another skill that participants described was remaining neutral and non-judgemental when speaking to families. Learning from her own experience, one participant has advised colleagues working with this population that a "gasp" followed by "oh my goodness, you're away from your family for 8 months?" when learning about such family events connotes pity or judgement.

Similarly, validating the experiences of families is a skill described by participants as an effective and important way to develop a trusting relationship. As part of his assessment, one participant routinely learns more about the family's military experiences and often acknowledges challenges by simply stating, "This must be exceptionally hard for you." In addition to developing a trusting relationship with MVFs, participants reported that being creative and flexible were some of the skills they employed when working with this population.

\section{Creativity and flexibility}

While participants worked toward being culturally competent, they adapted creative and flexible strategies whenever it was appropriate and possible. Having awareness and knowledge of how PTSD symptoms may affect how Veterans and their families manage in crowded waiting rooms, one participant made changes to her practice to eliminate a waiting room altogether.

Knowing that the Military Family Resource Centres (MFRC) can be an initial touchpoint for many military families arriving to a community, some participants developed collaborative relationships with their local MFRC to address the challenges of accessing health care in a new community. One participant described such an initiative:

But what I've done most recently is work with the base doc and the MFRC to say: All the new families are coming to be posted in [name of community] this summer. I'm going to do one intake clinic with those families to identify if there are children who need immediate referrals ... I hope that'll be a nice help. At least they'll have seen my face and [the families] will know that that is an option.

Participants described many incidents where there were significant delays in transferring of health records from one practitioner to the next, thus affecting the level of support they were able to provide families. In such cases, participants used a number of strategies to confirm the information provided by the family in order to provide necessary care:

So if it seems like they could benefit from a particular treatment, even though we don't have documentation of the actual diagnosis, and they're convinced that's what the child has, and it seems to be based on the history that that is accurate, I'm willing to go ahead and, and do something ... The other way we do it is to use a series of questionnaires, which we send to the families and to the teacher ... And we also send to their former physician, and that sometimes facilitates the process because the hope is that 
the former physician looked after the family. Even if it's not the same physician who saw them every time maybe that particular clinic would have access to some of the documents that we need.

Participants identified different ways in which they were able to provide necessary support and care to families in spite of the challenges families faced with accessing and continuing with health care services.

\section{Ecological context}

All of the participants acknowledged the influence of factors beyond their own competencies as affecting the experiences of health care for families. Participants found that collaborating with other health professionals or other health care teams, outside of their own practice has been beneficial as described this individual when she stated:

Ask them and their team. I would almost say that I'm, a little more - No, that's not true. I contact all team members if I need to, but it's really important to work as a team.

Although well intended, there were incidents whereby collaborations with other organizations led to increased confusion due to the lack of knowledge of resources and supports in the community, as described by this participant:

I was talking to Developmental Services. It seems like it was a bit of a wild goose chase a bit. Like, I would, I would be talking to somebody from Developmental Services. They would say, "You know, if you talk to the Family Military Resource Centre you can sometimes get some support or some funding for $x$ or $y$ that I was looking for."

Limitations to what can be provided by MFRCs has been a barrier for those working within the organization as they are often viewed as a one-stop shop to meet all the health needs of families.

Another ecological factor affecting the development of cultural competence in HCPs is the lack of formal training to adequately serve this population. Several participants identified their time as a trainee would have been an excellent opportunity to provide them with basic knowledge and understanding about MVF life and health-related issues. To overcome this external factor, many of the participants described how they had provided their interns/students with military cultural competency resources to review and opportunities to engage with MVFs as part of their training.

\section{DISCUSSION}

The purpose of this study was to identify aspects of military and Veteran family cultural competencies employed by HCPs. The four cultural competency domains, awareness, sensitivity, knowledge, and skills were identifiable in the stories and insights shared by the HCPs who participated in the study. The journey toward culturally competent practice can be traced through each of the cultural competency domains indicating that there is a point of entry into culturally competent care. For many, this begins with awareness, defined as the acknowledgement within the provider, that there are cultural differences between themselves and the group of people they are working with; ${ }^{44}$ however, the extent to which the wider population of Canadian HCPs have awareness is relatively unknown. A recent survey of $764 \mathrm{Ca}$ nadian pediatricians and pediatric specialists revealed that one-third of respondents incorrectly believed that the federal military health care system provided care to military-connected children and youth while half of the respondents were unsure who provided care to these children. ${ }^{45}$ Even though this study was conducted with one group of health care professionals, it provides an indication of the overall low levels of knowledge of military families in Canada.

Efforts are being made in Canada through collaborations between military family organizations and health associations to increase overall awareness. A joint effort between the Canadian Military and Veteran Families Leadership Circle and the College of Family Physicians of Canada developed and released a resource for family physicians who may work with military families. ${ }^{25}$ This document begins to raise awareness of MVFs living in communities across the country while also providing population-specific knowledge.

As noted in this current study, HCPs engage all four cultural competency domains when working with MVFs. While there are instances where a care action or a belief can be clearly understood as stemming from one or another cultural competency domain, approaches typically taken to develop cultural competency address multiple domains at the same time as this is a more accurate reflection of competent practice. An article was published with the specific aim of promoting military cultural awareness as a means of increasing overall military cultural competency to enhance civilian-based health services. ${ }^{46}$ Awareness, described in this study as conducting a self-inventory, encourages the health provider to be honest about their own political beliefs and 
values to ensure that the care and services they provide are not negatively influenced. ${ }^{46}$

Another study examined how competence in knowledge and skills shapes the readiness of mental health providers to provide care to service members, Veterans, and their families. This online survey of mental health professionals found that only $13 \%$ of respondents met the study's criteria for readiness to provide culturally competent and evidence-based care to this population. ${ }^{12}$ We also discovered that providers who work primarily in a military or Veterans Affairs (VA) setting were more likely to meet the study's criteria for delivery of culturally competent care, ${ }^{12}$ proposing that opportunities to develop skills in a clinical setting contribute to competency. This suggests that, in addition to developing awareness and/or knowledge, if provided with the opportunity, HCPs will develop culturally-informed skills when working with families.

The ecological context was acknowledged as affecting the ability of this study's participants to work as culturally competent health providers. Conditions to support the development of MVF cultural competency in HCPs need to be in place and may require leadership from the highest levels of government or their representatives. For example, in 2012, the former First Lady of the United States, Michelle Obama, and Dr. Jill Biden launched Joining Forces initiative $e^{47}$ " to engage individuals, communities, schools, and other organizations to come together to ensure that military and Veteran populations receive the support and health care they need. ${ }^{38}$ Following the announcement of Joining Forces, health professional regulatory bodies began committing to ensuring that their members working with military members, Veterans, and their families, were adequately prepared to do so. ${ }^{7,48,49}$ Creating an ecological context that supports culturally-informed curricula and learning opportunities may be required in Canada in order to adequately support pre-service HCPs.

\section{Limitations}

There was a narrow representation of the health care disciplines and subspecialties included in the study. Future research should include an expanded range of health professions and subspecialties (e.g., family therapists, child psychologists, occupational therapists working with children, emergency medicine physicians, etc.) to identify military and Veteran family cultural competencies required for specific professions. Another limitation of this study was the small sample size.

\section{Conclusion}

Identifying military and Veteran family cultural competencies in health care delivery ensures that the needs of this group are appropriately met. This study has identified that the cultural competency domains contribute to how this group of HCPs work with MVF in a culturally competent manner. Although each domain is distinct, when translated into practice, they overlap and work in unison propelling the practitioner toward culturally competent care. The ecological context has been described as having positive and negative effects on the ability of HCPs in this study to engage in culturally competent practice. This study has been able to add to the understanding of the health care experiences of MVFs in Canada and will make a significant contribution to future research to explore additional military family cultural competencies and the interconnections with the ecological context.

\section{REFERENCES}

1. National Defence and Canadian Forces Ombudsman. On the homefront: assessing the well-being of Canada's military families in the new millennium. In: Forces $\mathrm{NDaC}$, editor. Ottawa, ON: Office of the Ombudsman; 2013.

2. Muramatsu RS. Letters to the editor: A mounting need for military cultural competency in civilian behavioral health providers. Mil Med. 2013;178(2):121. Medline: 23495453

3. Coll JE, Weiss EL, Yarvis JS. No one leaves unchanged: insights for civilian mental health care professionals into the military experience and culture. Soc Work Health Care. 2011;50(7):487-500. https://doi.org/10. 1080/00981389.2010.528727. Medline:21846250

4. Westphal RJ, Convoy SP. Military culture implications for mental health and nursing care. Online J Issues Nurs. 2015;20(1):4. Medline:26824262

5. English AD. Understanding military culture: a Canadian perspective. Montreal: McGill-Queen's University Press; 2004.

6. Convoy SP, Westphal RJ. The importance of developing military cultural competence. J Emerg Nurs. 2013;39(6):591-4. https://doi.org/10.1016/j. jen.2013.08.010. Medline:24095051

7. Gleeson TD, Hemmer PA. Providing care to military personnel and their families: how we can all contribute. Acad Med. 2014;89(9):1201-3. https://doi.org/10.1097/acm.0000000000000368. Medline:24979291

8. Meyer E. Developing military cultural competency in health care providers. Acad Med. 2012;87(1):3. 
https://doi.org/10.1097/acm.0b013e31823a948c. Medline:22201627

9. Meyer EG. The importance of understanding military culture. Acad Psychiatry. 2015;39(4):416-8. https://doi.org/10.1007/s40596-015-0285-1. Medline:25690349

10. Meyer EG, Writer BW, Brim W. The importance of military cultural competence. Curr Psychiatry Rep. 2016;18(3):26. https://doi.org/10.1007/s11920-0160662-9. Medline:26830884

11. Miller KE, Finn JA, Newman E. Are communities ready? Assessing providers' practices, attitudes, and knowledge about military personnel. Prof Psychol Res Pr. 2014;45(6):398-404. https://doi.org/10.1037/ a0036774.

12. Tanielian T, Farris C, Batka C, et al. Ready to serve: community-based provider capacity to deliver culturally competent, quality mental health care to Veterans and their families. Santa Monica, CA: Library of Congress; 2014.

13. Butler LD, Linn BK, Meeker MA, et al. "We don't complain about little things": views of Veterans and military family members on health care gaps and needs. Mil Behav Health. 2015;3(2):116-24. https://doi.org/ 10.1080/21635781.2015.1009209.

14. Kim-Godwin YS, Clarke PN, Baron L. A model for the delivery of culturally competent community care. J Adv Nurs. 2001;35(6):918-25. https://doi.org/10.1046/ j.1365-2648.2001.01929.x. Medline: 11555040

15. Willis DG, Porche DJ. Envisioning and advancing marginalized men's health disparities scholarship: the marginality-cultural competence integrative framework (M-CCIF). Issues Ment Health Nurs. 2006;27(4):425-42. https://doi.org/10.1080/01612840600569682. Medline: 16546939

16. Teal CR, Street RL. Critical elements of culturally competent communication in the medical encounter: a review and model. Soc Sci Med. 2009;68(3):533-43. https://doi.org/10.1016/j.socscimed.2008.10.015. Medline: 19019520

17. Uriarte JA, Cummings AD, Lloyd LE. An instructional design model for culturally competent community health worker training. Health Promot Pract. 2014;15(1_Suppl):56S-63S. https://doi. org/10.1177/1524839913517711. Medline:24578366

18. Beard KV, Gwanmesia E, Miranda-Diaz G. Culturally competent care: using the ESFT model in nursing. Am J Nurs. 2015;115(6):58-62. https://doi. org/10.1097/01.naj.0000466326.99804.c4. Medline: 26018010

19. Hoge MA, Tondora J, Marrelli AF. The fundamentals of workforce competency: implications for behavioral health. Adm Policy Ment Health.
2005;32(5-6):509-31. https://doi.org/10.1007/ s10488-005-3263-1. Medline:16082795

20. Marrelli AF, Tondora J, Hoge MA. Strategies for developing competency models. Adm Policy Ment Health. 2005;32(5-6):533-61. https://doi.org/10.1007/ s10488-005-3264-0. Medline:16082796

21. Shippmann JS, Ash RA, Batjtsta M, et al. The practice of competency modeling. Pers Psychol. 2000;53(3):703-40. https://doi. org/10.1111/j.1744-6570.2000.tb00220.x.

22. Ohye BY, Roizner M, Laifer LM, et al. Training clinicians to provide culturally competent treatment to military-connected children: a collaborative model between the Massachusetts Society for the Prevention of Cruelty to Children and the Red Sox Foundation and Massachusetts General Hospital Home Base Program. Prof Psychol Res Pr. 2017;48(3):149-55. https://doi. org/10.1037/pro0000143.

23. York J, Sternke LM, Myrick DH, et al. Development of Veteran-centric competency domains for psychiatric-mental health nurse practitioner residents. J Psychosoc Nurs Ment Health Serv. 2016;54(11):31-6. https://doi.org/10.3928/02793695-20161024-06. Medline:27805714

24. College of Family Physicians of Canada. Best advice: caring for military families in the patient's medical home. Mississauga, ON: 2017 Sep [cited 2019 Jul 12]. Available from: https://www.cfpc.ca/uploadedFiles/ CPD/BAG_Military_Families_EN_FINAL.pdf.

25. College of Family Physicians of Canada; Canadian Military and Veteran Families Leadership Circle. Family physicians working with military families. Mississauga, ON; 2016 [cited 2019 Jul 12]. Available from: https:// www.cfpc.ca/uploadedFiles/Military\%20Family\%20 Physician\%20Guide_E.pdf.

26. Cramm H, Tam-Seto L. Occupational therapy and the families of military and Veterans. Occup Ther Now. 2018;11(3).

27. Edgelow M, Cramm H. Building communities of care for military children and families. Occup Ther Now. 2015;17(5):3.

28. Edgelow M, Cramm H. Occupational therapy leadership in military, Veteran and family health. Occup Ther Now. 2015;17(5):23.

29. Canadian Association of Occupational Therapists (CAOT). Working for the Canadian Armed Forces and Veterans Affairs Canada: a guidance document for occupational therapists. Ottawa: CAOT; 2017.

30. Marshall T. Social work and the treatment of OSIs [homepage on the Internet]. Ottawa: Canadian Association of Social Workers; n.d. [cited 2019 Jul 12]. Available from: http://www.casw-acts.ca/en/socialwork-and-treatment-osis. 
31. Canadian Psychological Association. Canadian Psychological Association. Psychology in the military 16 section [homepage on the Internet]. Ottawa: The Association; c2016 [cited 2019 Jul 12]. Available from: https://cpa.ca/sections/psychologyinthemilitary/.

32. Canadian Nurses Association. Fact sheet: Peace and health. Ottawa: Canadian Nurses Association; 2009. Available from: http://cna-aiic.ca/ /media/cna/ page-content/pdf-fr/fs27_peace_health_2009_e.pdf.

33. Creswell J, Plano Clark VL. Designing and conducting mixed methods research. 2nd. ed. Thousand Oaks, CA: Sage; 2011.

34. Coetzer A, Redmond JL, Sharafizad J. Decision making regarding access to training and development in medium-sized enterprises: an exploratory study using the Critical Incident Technique. Eur J Train Dev. 2012;36(4):426-47. https://doi. org/10.1108/03090591211220348.

35. Janes N, Fox M, Lowe M, et al. Facilitating best practice in aged care: exploring influential factors through critical incident technique. Int J Older People Nurs. 2009;4(3):166-76. https://doi.org/10.1111/j.17483743.2009.00169.x. Medline:20925773

36. Flanagan JC. The critical incident technique. Psychol Bull. 1954;51(4):327-58. https://doi.org/10.1037/ h0061470. Medline: 13177800

37. Teddlie C, Yu F. Mixed methods sampling: a typology with examples. J Mix Methods Res. 2007;1(1):77-100. https://doi.org/10.1177/1558689806292430.

38. Hohashi N, Honda J. Development of the concentric sphere family environment model and companion tools for culturally congruent family assessment. J Transcult Nurs. 2011;22(4):350-61. https://doi. org/10.1177/1043659611414200. Medline:21949062

39. Purnell L. The Purnell Model for cultural competence. J Multicult Nurs Health. 2005;11(2):7-15.

40. Suh EE. The model of cultural competence through an evolutionary concept analysis. J Transcult Nurs. 2004;15(2):93-102. https://doi. org/10.1177/1043659603262488. Medline: 15070491

41. Ritchie J, Spencer L. Qualitative data analysis for applied policy research. Huberman A, Miles M, editors. Thousand Oaks, CA: SAGE Publications, Inc.; 2002.

42. MAXQDA qualitative data analysis software, version 12.3.2. VERBI Software-Consult-Sozialforschung GmbH. Berlin, Germany; 1989-2017.

43. Council on Social Work Education. Advanced social work practice in military social work. Alexandria, VA: Council on Social Work Education; 2010.

44. Schim SM, Doorenbos AZ. A three-dimensional model of cultural congruence: framework for intervention. J Soc Work End Life Palliat Care. 2010;6(3-4):25670. https://doi.org/10.1080/15524256.2010.529023. Medline:21132602
45. Cramm H, Mahar AL, Tam-Seto L, et al. Providing care to children and youth from miltiary families. Ottawa: Canadian Paediatric Surveillance Program; 2018.

46. Luby CD. Promoting military cultural awareness in an off-post community of behavioral health and social support service providers. Adv Soc Work. 2012;13(1):67-82. https://doi.org/10.18060/1873.

47. White House (President Barack Obama). Joining forces. Support for our service members, Veterans, and their families [homepage on the Internet]. n.d. [cited 2019 Jul 12]. Washington, DC: The White House. Available from: https://obamawhitehouse.archives.gov/joiningforces.

48. Elliott B, Patterson B. Joining forces: the status of military and Veteran health care in nursing curricula. J Prof Nurs. 2017;33(2):145-52. https://doi.org/10.1016/j. profnurs.2016.06.006. Medline:28363389

49. Wooten NR, Smith-Osborne A, Hassan, A. Guest editorial: introduction to the special issue. J Soc Work Educ. 2015;51(Suppl. 1):S1-S5. https://doi.org/10.10 80/10437797.2015.1001269. Medline:26778908

\section{AUTHOR INFORMATION}

Linna Tam-Seto, PhD, MScOT (Post-Professional), $\mathrm{BScOT}$, BA, is a Post-Doctoral Research Fellow in the Health Studies and Policy Research Institute at Queen's University. Her research interests include understanding the role of culture on the health experiences of military community members. Her research interests also include understanding the impact of military life during service and post-release on the health and well-being of military and Veteran families within the Canadian context.

Terry Krupa, PhD, MEd, BScOT, is a Professor Emerita in the School of Rehabilitation Therapy, Queen's University. Her research program has included studies focusing on the identification of professional competencies in a range of health care service delivery contexts.

Heather Stuart, PhD, MA, BA, is a social epidemiologist specializing in psychiatric epidemiology and mental health services research. She is a Full Professor and Bell Canada Mental Health and Anti-stigma Research Chair in the Department of Public Health Sciences at Queen's University, Kingston, Ontario.

Patricia Lingley-Pottie, PhD, BNRN, is cofounder, $\mathrm{CEO} /$ President - Strongest Families Institute; Assistant Professor - Dalhousie University, Psychiatry. Patricia has expertise in research methods, scale development and the conduct of randomized clinical trials with a focus on: psychological research; using technology to deliver evidencebased interventions; ehealth systems and scale-up; military families; distance therapeutic alliance, distance treatment experience and barriers to care. 
Alice Aiken, $\mathrm{PhD}, \mathrm{MSc}, \mathrm{BScPT}, \mathrm{BSc}$, is the Vice President Research \& Innovation at Dalhousie University in Halifax, Canada. She is an active researcher focused on health systems transformation and evidence-informed policy-making. Dr. Aiken is currently the Vice Chair of the Governing Council of the Canadian Institutes of Health Research (CIHR) and Chair of the board of Research Nova Scotia.

Heidi Cramm, PhD, MScOT (Post-Professional), MA, $\mathrm{BScOT}, \mathrm{BA}$ (Hons), is an occupational therapist and Associate Professor in the School of Rehabilitation Therapy at Queen's University in Kingston (ON). Her research focuses on military and Veteran family health, with an emphasis on mental health.

\section{COMPETING INTERESTS}

None declared.

This article has been peer reviewed.

\section{CONTRIBUTORS}

All authors conceived, designed, researched, and drafted the manuscript and approved the final version submitted for publication.

\section{FUNDING}

None declared. 